\title{
A Novel PKC Inhibitor Shows Promise for Amphetamine Use Disorders
}

\author{
Amy H Newman ${ }^{*, I}$ \\ 'Medicinal Chemistry Section, Molecular Targets and Medications Discovery Branch, National Institute on Drug Abuse, Intramural Research \\ Program, National Institutes of Health, Baltimore, MD, USA
}

Neuropsychopharmacology (2017) 42, 1929-1930; doi:10.1038/npp.2017.1 I6; published online 28 June 2017

The 2016 U.S. Surgeon General's report on alcohol, drugs and health in America is entitled 'Facing Addiction in America' (https://addiction.surgeongeneral.gov/surgeon-gen erals-report.pdf). This comprehensive and public account provides scientific evidence to define 'substance use disorder' as a chronic medical condition that takes its toll on our public health care and judicial systems in an economically unsustainable way. As $>20$ million Americans directly suffer from substance use disorders, the development of prevention and treatment options for addiction as alternatives to incarceration is the just solution to this burgeoning global problem. Unfortunately, despite decades of research, effective pharmacotherapy, as part of a treatment regimen for people who abuse or are addicted to amphetamines, has yet to be discovered (Brensilver et al, 2013).

In this issue of Neuropsychopharmacology, Carpenter and colleagues (Carpenter et al, 2017) propose a new class of drugs that block protein kinase C (PKC), a protein that enhances amphetamine-stimulated dopamine efflux. The primary mechanism(s) underlying the psychostimulant and reinforcing effects of the amphetamines is the inhibition of dopamine uptake via competition with dopamine at the dopamine transporter (DAT) and the promotion of dopamine efflux via reverse transport. Hence, inhibition of amphetamine-stimulated dopamine efflux by inhibiting PKC would ultimately decrease the release of dopamine, which would be predicted to decrease the behavioral effects produced by the amphetamines that can lead to their abuse.

Interestingly, tamoxifen, an estrogen receptor antagonist and a well-known treatment for breast cancer, is also a PKC inhibitor, and indeed, this mechanism of action has been purported to also play a role in its antitumor efficacy (O'Brian et al, 1985). Moreover, tamoxifen has been evaluated as a potential medication for the treatment of

\footnotetext{
*Correspondence: $\mathrm{Dr} \mathrm{AH}$ Newman, Molecular Targets and Medications Discovery Branch, National Institute on Drug Abuse, Intramural Research Program (NIDA IRP), NIH, 333 Cassell Drive Baltimore, MD 21224, USA, Tel: 443740 2887, Fax: 443740 21। I, E-mail: amy.newman@nih.gov

Received 22 May 2017; accepted 27 May 2017; accepted article preview online 8 June 2017
}

bipolar disorder due to its PKC inhibitor profile and ability to penetrate the blood brain barrier (Armani et al, 2014). As preclinical models of bipolar disorder involve amphetamineinduced hyperactivity in laboratory animals, the possibility that a brain permeant PKC inhibitor might be an effective medication strategy for amphetamine use disorders was apparent. Indeed, the Gnegy group recently reported the $\mathrm{PKC} \beta$ inhibitors, enzastaurin and ruboxistaurin, to attenuate amphetamine-stimulated dopamine efflux while having no effect on DAT function (Zestos et al, 2016), lending further support to this hypothesis.

Prior to the present set of experiments, this group teamed up with medicinal chemists to follow-up on a series of tamoxifen analogues that had previously been synthesized as antitumor agents, in order to improve PKC inhibition potency while reducing estrogen receptor affinity, which was deemed to cause undesired side effects (Carpenter $e t$ al, 2016). They took advantage of previous structure-activity relationship studies that showed substitution of the ethyl moiety in tamoxifen with a $\mathrm{CN}$ group significantly improved PKC affinity (Figure 1, in blue). By elaborating the molecule to include a bis(4-(2-(4-methylpiperazin-1-yl)ethoxy)phenyl) substitution (Figure 1, modifications in red), creating a

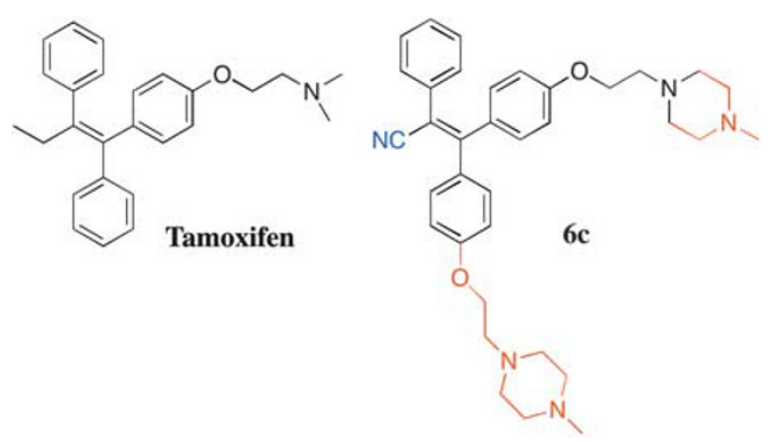

Figure I Chemical structures of tamoxifen and analogue $\mathbf{6 c}$. Substitution of the ethyl moiety in tamoxifen with a $\mathrm{CN}$ group (in blue) significantly improved PKC affinity. Further elaboration (in red) to include a bis(4-(2-(4methylpiperazin-|-y|)ethoxy)phenyl) substitution gave this novel and selective PKC inhibitor. 
bivalent structure, the resulting lead compound $6 \mathrm{c}$ was a potent $\mathrm{PKC}$ inhibitor $\left(\mathrm{IC}_{50}=80 \mathrm{nM}\right)$ without detectable binding to the estrogen receptor $\left(K_{\mathrm{i}}>10 \mu \mathrm{M}\right)$. Compound $6 \mathrm{c}$ possessed physicochemical properties (eg, $\operatorname{cLogP}=5.24$, tPSA $=55.2$ ) that predicted brain permeability and a drug-like profile; this compound was chosen to be the lead molecule in the present study.

Building on previous findings, the Gnegy group has now demonstrated that $6 \mathrm{c}$ more potently inhibits PKC than tamoxifen and reduces amphetamine-stimulated dopamine efflux. Additionally, $\mathbf{6 c}$ does not directly bind to DAT and is more potent in inhibiting amphetamine-stimulated dopamine efflux than blocking dopamine uptake via the DAT, indicating that $6 \mathrm{c}$ is not a DAT blocker and instead reverses transport through a PKC mechanism. Gratifyingly, $\mathbf{6 c}$ is brain permeant and effectively blocks amphetamineinduced locomotor stimulation. Moreover, $6 \mathrm{c}$ reduces amphetamine but not sucrose self-administration (fixed ratio-5 reinforcement schedule) with an $18 \mathrm{~h}$ pretreatment time, suggesting long lasting effects (Carpenter et al, 2017).

Of course, these are early days in the world of medication development. Evaluation of $\mathbf{6 c}$ on the inverted U-shaped dose-response curve of amphetamine self-administration and responding under a progressive ratio reinforcement schedule will determine if it does indeed dampen the rewarding effects of this addictive class of drugs. Testing in additional preclinical models of psychostimulant addiction and relapse, as well as models of bipolar disorder and other dopamine-related neuropsychiatric disorders should follow this exciting lead. Perhaps $\mathbf{6 c}$ or a newer generation of tamoxifen analogues in the future will make the needed breakthrough in pharmacotherapeutic treatment options for people who suffer from amphetamine use disorders. Indeed,
'Facing Addiction in America' and around the world is just the beginning. Combatting it with therapeutic options for both prevention and treatment is our charge and our challenge.

\section{FUNDING AND DISCLOSURE}

AHN is supported by the NIDA-Intramural Research Program. The author declares no conflict of interest.

\section{REFERENCES}

Armani F, Andersen ML, Galduróz JC (2014). Tamoxifen use for the management of mania: a review of current preclinical evidence. Psychopharmacology 231: 639-649.

Brensilver M, Heinzerling KG, Shoptaw S (2013). Pharmacotherapy of amphetamine-type stimulant dependence: an update. Drug Alcohol Rev 32: 449-460.

Carpenter C, Zestos AG, Altshuler R, Sorenson RJ, Guptaroy B, Showalter HD et al (2017). Direct and systemic administration of a CNS-permeant tamoxifen analog reduces amphetamineinduced dopamine release and reinforcing effects. Neuropsychopharmacology (this issue).

Carpenter C, Sorenson RJ, Jin Y, Klossowski S, Cierpicki T, Gnegy $\mathrm{M}$ et al (2016). Design and synthesis of triarylacrylonitrile analogues of tamoxifen with improved binding selectivity to protein kinase C. Bioorg Med Chem 24: 5495-5504.

O'Brian CA, Liskamp RM, Solomon DH, Weinstein IB (1985). Inhibition of protein kinase C by tamoxifen. Cancer Res 45: 2462-2465.

Zestos AG, Mikelman SR, Kennedy RT, Gnegy ME (2016).) PKC $\beta$ inhibitors attenuate amphetamine-stimulated dopamine efflux. ACS Chem Neurosci 7: 757-766. 